
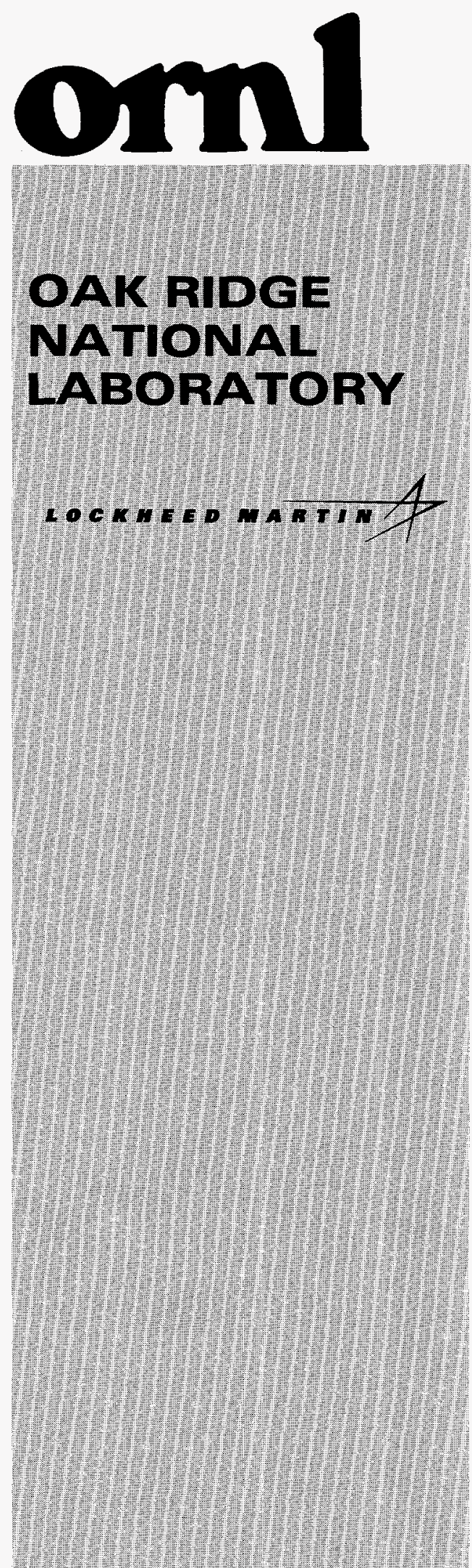

MANAGED AND OPERATED BY

LOCKHEEO MARTW ENERGY RESEARCH CORPOBATION FOR THE UNTED STATES DEPARTMENT OF ENERGY

ORNL.27 (3.06)
ORNL/TM-13754

\section{Corrosion of Type 316L Stainless Steel in a Mercury Thermal Convection Loop}

\author{
S. J. Pawel \\ J. R. DiStefano \\ E. T. Manneschmidt
}


This report has been reproduced directly from the best available copy.

Available to DOE and DOE contractors from the Office of Scientific and Technical Information, P. O. Box 62, Oak Ridge, TN 37831; prices available from (423) 576-8401.

Available to the public from the National Technical Information Service, U. S. Department of Commerce, 5285 Port Royal Rd., Springfield, VA 22161.

This report was prepared as an account of work sponsored by an agency of the United States Government. Neither the United States Government nor any agency thereof, nor any of their employees, makes any warranty, express or implied, or assumes any legal liability or responsibility for the accuracy, completeness, or usefuiness of any information, apparatus, product, or process disclosed, or represents that its use would not infringe privately owned rights. Reference herein to any specific commercial product, process, or service by trade name, trademark, manufacturer, or otherwise, does not necessarily constitute or imply its endorsement, recommendation, or favoring by the United States Government or any agency thereof. The views and opinions of authors expressed herein do not necessarily state or reflect those of the United States Government or any agency thereof. 


\section{DISCLAIMER}

Portions of this document may be illegible in electronic image products. Images are produced from the best available original document. 
ORNL/TM-13754

\title{
CORROSION OF TYPE 316L STAINLESS STEEL IN A MERCURY THERMAL CONVECTION LOOP
}

\author{
S. J. Pawel, J. R. DiStefano, and E. T. Manneschmidt
}

Date Published: April 1999

Prepared for the

U.S. Department of Energy

Spallation Neutron Source

Prepared by the OAK RIDGE NATIONAL LABORATORY

Oak Ridge, Tennessee 37831-6285 managed by

Lockheed Martin Energy Research Corporation for the

U.S. DEPARTMENT OF ENERGY

under contract DE-AC05-96OR22464 


\section{CONTENTS}

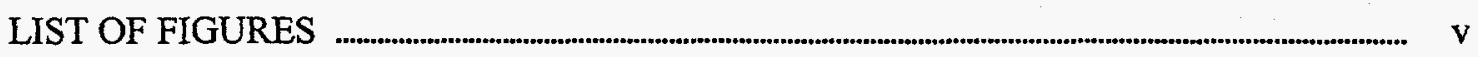

LIST OF TABLES …............................................................................................................................................ vii

ABSTRACT

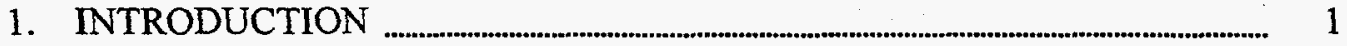

2. EXPERIMENTAL_................................................................................................................ 3

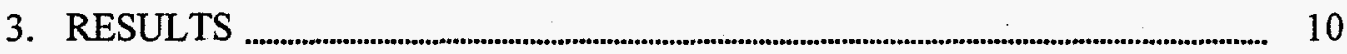

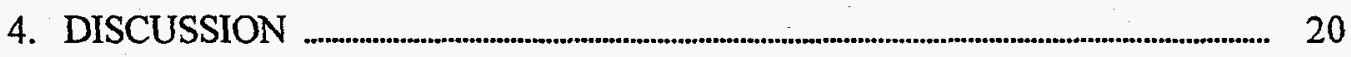

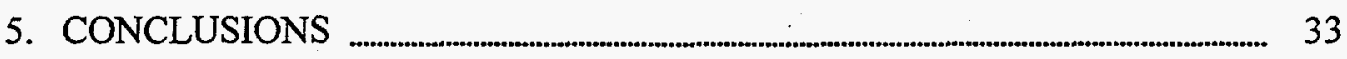

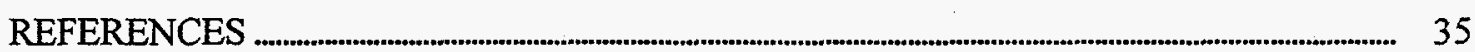

ACKNOWLEDGEMENTS _.................................................................................................................... 37 



\section{LIST OF FIGURES}

\section{$\underline{\text { PAGE }}$}

Fig. 1. Thermal convection loop design. The diagram is roughly to scale; distance between thermocouple wells on each vertical section is $67 \mathrm{~cm}$ in the actual loop

Fig. 2. Photograph of thermal convection loop prior to wrapping with insulation and placement of air tubes for cooling cold leg 5

Fig. 3. Coupon for exposure inside thermal convection loop. Dimensions given in inches from shop fabrication drawing

Fig. 4. 316L SS coupons exposed in the hot leg of loop \#1. Coupons 1-8 in the top row, 9-16 in the second row, etc.

Fig. 5. 316L SS coupons exposed in the cold leg of loop \#1. Coupons 1-8 in the top row, $9-16$ in the second row, etc.

Fig. 6. Specimen weight loss as a function of temperature (position) in loop \#1 13

Fig. 7. As-polished cross section of $316 \mathrm{~L} \mathrm{SS} \mathrm{specimen} \mathrm{from} \mathrm{the} \mathrm{top} \mathrm{of} \mathrm{the} \mathrm{hot} \mathrm{leg}$ $\left(305^{\circ} \mathrm{C}\right)$ in loop $\# 1$ [98-1797-01]

Fig. 8. Etched (10\% oxalic acid, electrolytic) cross section of $316 \mathrm{~L}$ SS specimen from the top of the hot leg $\left(305^{\circ} \mathrm{C}\right)$ in loop \#1 [98-1797-04]

Fig. 9. As-polished cross section of unexposed 316L SS specimen [98-0028-03]

Fig. 10. Backscattered electron image of as-polished cross section of $316 \mathrm{~L}$ SS specimen from top of hot leg $\left(305^{\circ} \mathrm{C}\right)$ in loop \#1 [EAK-4818]

Fig. 11. Representative microprobe data from 316L specimen from the top of the hot leg $\left(305^{\circ} \mathrm{C}\right)$ in loop $\# 1$. Note that peak associated with nickel is absent from the scan on corroded material and the peaks associated with chromium are significantly reduced

Fig. 12. Relationship of surface ferrite measurement and coupon weight loss in loop \#1... 19

Fig. 13. Analysis of weight loss data following the approach of Epstein [2] 28

Fig. 14. Analysis of weight loss data following the approach of Tortorelli and DeVan [7] 



\section{LIST OF TABLES}

$\underline{\text { PAGE }}$

Table 1. Composition of 316L SS loop tubing material and coupons. Data from mill certification for material, given in weight percent

Table 2. Nominal temperatures at each "corner" of the thermal convection loops, strip chart print out of temperatures for each thermocouple indicate $+1-2^{\circ} \mathrm{C}$ drift over the duration of the experiment at each location 


\title{
CORROSION OF TYPE 316L STAINLESS STEEL IN A MERCURY THERMAL CONVECTION LOOP
}

\author{
S. J. Pawel, J. R. DiStefano, and E. T. Manneschmidt
}

\begin{abstract}
Two thermal convection loops fabricated from $316 \mathrm{~L}$ stainless steel containing mercury $(\mathrm{Hg})$ and $\mathrm{Hg}$ with 1000 wppm gallium $(\mathrm{Ga})$, respectively, were operated continuously for about $5000 \mathrm{~h}$. In each case, the maximum loop temperature was constant at about $305^{\circ} \mathrm{C}$ and the minimum temperature was constant at about $242^{\circ} \mathrm{C}$. Coupons in the hot leg of the $\mathrm{Hg}$-loop developed a porous surface layer substantially depleted of nickel and chromium, which resulted in a transformation to ferrite. The coupon exposed at the top of the hot leg in the $\mathrm{Hg}$-loop experienced the maximum degradation, exhibiting a surface layer extending an average of $9-10 \mu \mathrm{m}$ after almost $5000 \mathrm{~h}$. Analysis of the corrosion rate data as a function of temperature (position) in the Hg-loop suggests wetting by the mercury occurred only above about $255^{\circ} \mathrm{C}$ and that the rate limiting step in the corrosion process above $255^{\circ} \mathrm{C}$ is solute diffusion through the saturated liquid boundary layer adjacent to the corroding surface. The latter factor suggests that the corrosion of $316 \mathrm{~L}$ stainless steel in a mercury loop may be velocity dependent. No wetting and no corrosion were observed on the coupons and wall specimens removed from the $\mathrm{Hg} / \mathrm{Ga}$ loop after $5000 \mathrm{~h}$ of operation.
\end{abstract}

\section{INTRODUCTION}

The Spallation Neutron Source (SNS) is a research facility that will generate neutrons via interaction of a $1.0 \mathrm{GeV}$ proton beam and a flowing mercury target. Type $316 \mathrm{~L} / 316 \mathrm{LN}$ stainless steel (SS) has been selected as the target containment material based on a favorable combination of several factors, including resistance to corrosion and radiation damage and the absence of a significant ductile-brittle transition temperature [1].

The energy deposited in the target is transported by two separate mercury flow streams: one to transport heat generated in the interior target region and one to cool the containment vessel where it intersects the proton beam. Three dimensional computational

*Research sponsored by the U.S. Department of Energy, Spallation Neutron Source 
fluid dynamics simulations of the expected conditions in the target presently predict a maximum bulk mercury temperature of about $160^{\circ} \mathrm{C}$. Further, assuming adequate thermal contact, the maximum container wall temperature is expected to be about $130^{\circ} \mathrm{C}$. The nominal temperature of the mercury entering the target is expected to be near ambient.

One of the potential compatibility problems under investigation in support of the SNS Project is thermal gradient mass transfer. In this form of corrosion, dissolution of the container material by the liquid in relatively high temperature (higher solubility) regions is accompanied by deposition of solute in relatively colder regions [2]. As a result, corrosion of the high temperature region is not limited by system equilibrium and is potentially accelerated over what would be experienced in an isothermal/stagnant system. In addition, in the cold regions, deposition of solute material has been known to cause flow problems and can even plug flow paths in liquid metal loops [3]. Among the major alloying elements of stainless steels, nickel is expected to have the highest solubility in mercury [4] at SNS operating temperatures, and therefore this element may be the most susceptible to mass transfer.

At the expected SNS operating temperatures, pure mercury does not readily wet $316 \mathrm{~L} / 316 \mathrm{LN}$ SS. Without chemical wetting (characterized macroscopically by a low contact angle), any potential corrosion process is inhibited. However, mercury can be made to wet $316 \mathrm{~L} / 316 \mathrm{LN}$ in an air environment by raising the temperature to $225-275^{\circ} \mathrm{C}$ [5]. Despite the relatively low operating temperatures, wetting may be promoted in the SNS by the presence of hot spots, radiation damage in the presence of $\mathrm{Hg}$, and by the generation of fresh (oxide-free) surfaces that result from potential cavitation and thermal shock/fatigue loading 
to which the target material will be exposed. Accordingly, to examine potential "worst case" corrosion, it is desirable to develop wetting in the tests for material compatibility with mercury.

To examine the potential for thermal gradient mass transfer in the liquid mercury target system, two thermal convection loops (TCLs) fabricated from 316L SS were operated for about $5000 \mathrm{~h}$. Both loops were operated at temperatures higher than expected in the SNS to obtain wetting and exacerbate corrosion. One loop was operated with pure mercury as the fluid while the other was operated under identical conditions with 1000 wppm of gallium added to the mercury. Because gallium has a reputation as an aggressive metal that wets many materials and because it has some solubility in mercury (even at room temperature), the gallium was added to the mercury in an attempt to increase the tendency of the liquid metal to wet the stainless steel specimens and containment. This document describes the operation of the TCLs and the results obtained.

\section{EXPERIMENTAL}

Loop Assembly and Experimental Procedure

Loop Fabrication

A schematic of the thermal convection loop design is shown in Fig. 1 and an assembled loop is shown in Fig. 2. The loop proper was fabricated of mill-annealed 316L SS welded tubing (25.4 $\mathrm{mm}$ OD, $1.8 \mathrm{~mm}$ wall) with a composition given in Table 1. The thermocouple wells were $316 \mathrm{~L}$ SS seamless tubing $(6.4 \mathrm{~mm} \mathrm{OD}, 0.7 \mathrm{~mm}$ wall) that protruded about halfway into the flow channel from the ID surface. Valves and other metallic accessories (connectors, containers, transfer lines, etc) were also 316 or $316 \mathrm{~L}$ SS. 


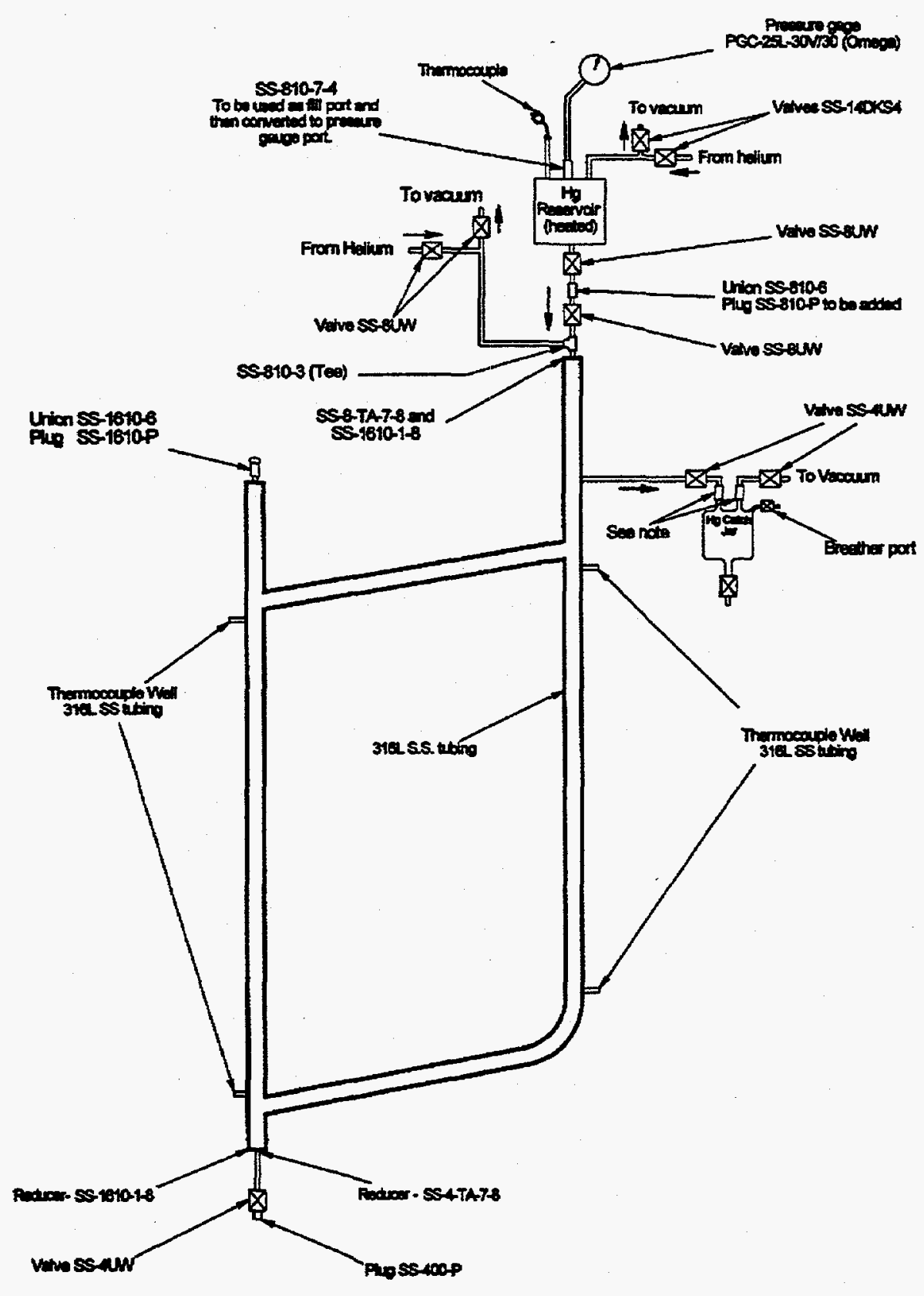

Fig. 1. Thermal convection loop design. The diagram is roughly to scale; distance between thermocouple wells on each vertical section is $67 \mathrm{~cm}$ in the actual loop. 


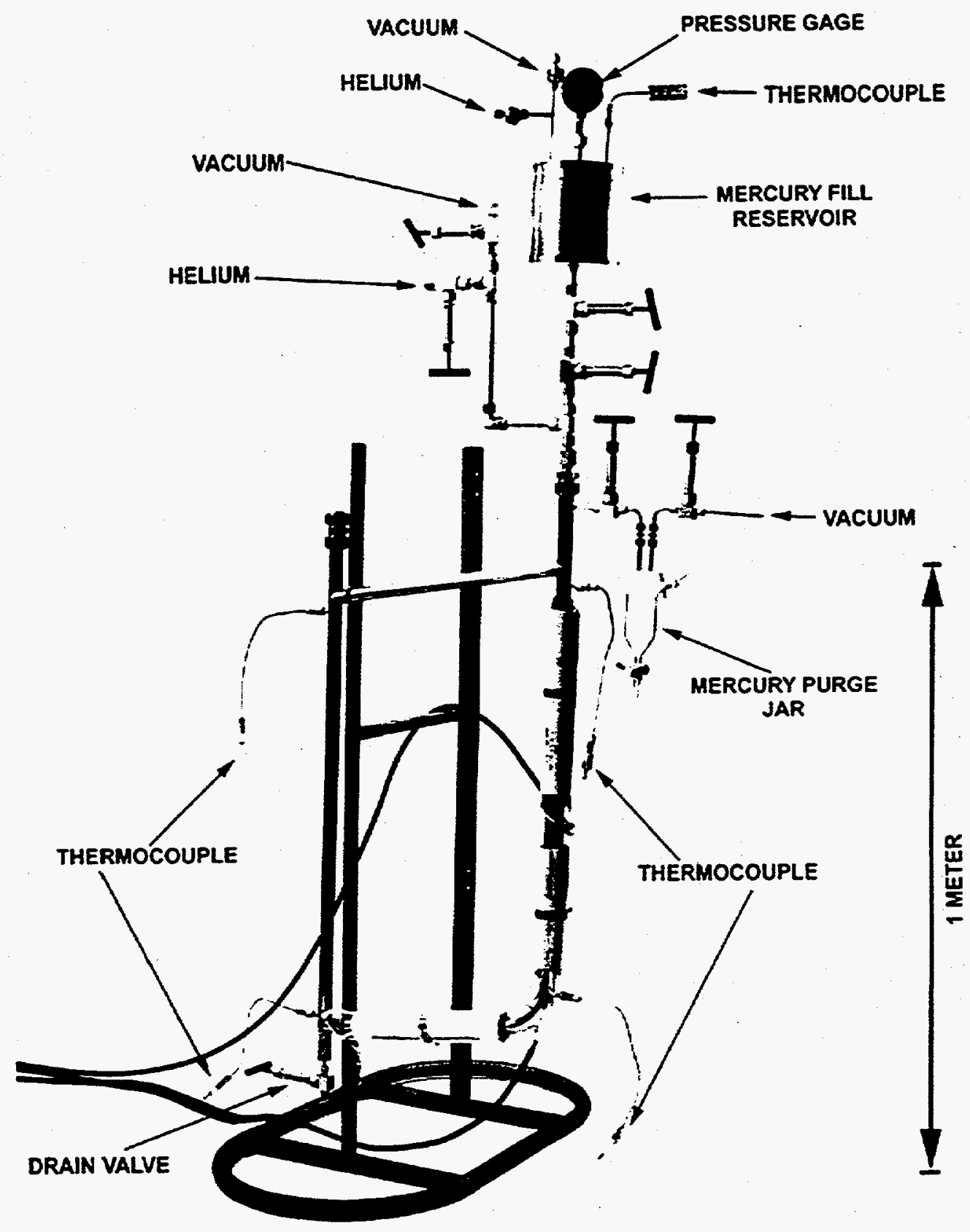

\section{MERCURY THERMAL CONVECTION LOOP}

Fig. 2. Photograph of thermal convection loop prior to wrapping with insulation and placement of air tubes for cooling cold leg. 
Each loop was fitted with a string of $316 \mathrm{~L}$ SS coupons wired together in each of the heated and cooled vertical sections (typically termed the "hot leg" and "cold leg," respectively). The coupon design is shown in Fig. 3 and the coupon composition is given in Table 1. The coupons were stacked together and interlocked via the square notch on each end of the specimen. [Alternating coupons are thus turned $90^{\circ}$ to each other to facilitate close spacing with little movement relative to each other.] A continuous 316 SS wire (about $0.50 \mathrm{~mm}$ diameter) was looped through the small holes in the corner of each coupon in order to secure the specimens in the close-packed arrangement. The end of each wire was welded to the bottom of each respective vertical leg to keep the chain of specimens from floating to the top of the mercury.

Each specimen string consisted of 32 coupons. The specimens were individually numbered, cleaned ultrasonically in acetone, and weighed prior to assembly of the chain. All specimens and wires were handled with gloves and tweezers during the stacking and wiring activities. Once in place, coupons in the chain extended the entire length of each vertical leg (between the thermocouple well positions).

Table 1. Composition of $316 \mathrm{~L}$ SS loop tubing material and coupons. Data from mill certification for material, given in weight percent.

\section{Loops $\quad$ Coupons}

$\begin{array}{lcc}\mathrm{C} & 0.013 & 0.018 \\ \mathrm{Cr} & 16.75 & 16.10 \\ \mathrm{Ni} & 10.19 & 10.10 \\ \mathrm{Mo} & 2.12 & 2.15 \\ \mathrm{Si} & 0.34 & 0.50 \\ \mathrm{Mn} & 1.84 & 1.73 \\ \mathrm{Cu} & 0.30 & 0.29 \\ \mathrm{~S} & 0.014 & 0.005 \\ \mathrm{P} & 0.028 & 0.028 \\ \mathrm{~N} & 0.046 & 0.030 \\ \mathrm{Cb} & 0.17 & --- \\ \mathrm{Fe} & \text { bal } & \text { bal }\end{array}$



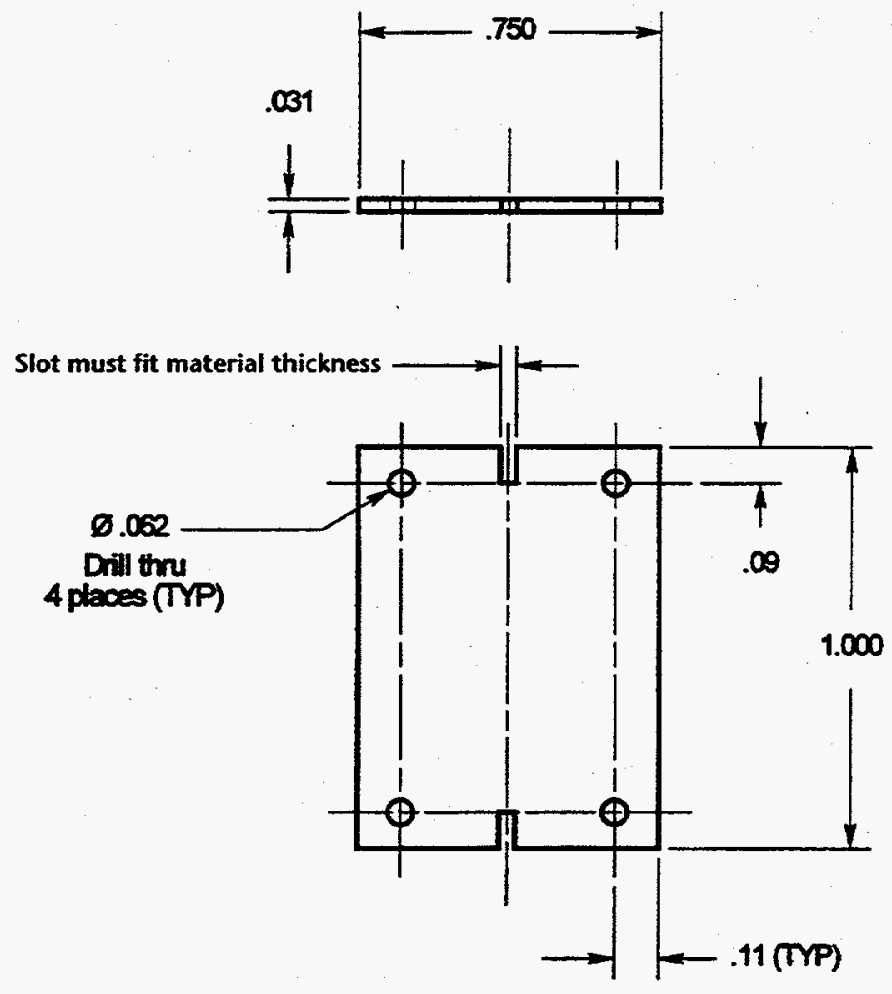

\section{DO NOT SHEAR}

Tolerances

$X . X X X=+1-0.005^{\prime \prime}$

$X . X X=+-0.01 "$

$X . X=+l-0.1^{\prime \prime}$

All surfaces shall be parallel and perpendicular as appropriate within 0.002". All dimensions in inches.

Material

316L Stainless Steel

Fig. 3. Coupon for exposure inside thermal convection loop. Dimensions given in inches from shop fabrication drawing.

After fabrication and coupon placement, the loops were filled with methanol as a final leak-check of the assembly. However, during this procedure, it became apparent that the $316 \mathrm{~L}$ SS loop tubing had not been adequately cleaned in the course of fabrication. The primary indicator of poor cleanliness was discolored methanol with machining chips/debris drained from the loop after the leak check. In addition, a black residue was collected on a cotton swab dragged along the tube ID. Subsequently, rinsing with trichlorethylene (ambient 
and again heated) proved unsuccessful for removing the black residue from the tube ID. However, a steam treatment (50 psig, two 10 -minute periods, steam in at top of hot leg, condensate out bottom of cold leg) was found to be relatively effective for removing the remaining machining debris and all but tiny traces of the black residue. After two subsequent flushes with methanol and vacuum drying, the loops were deemed ready to be filled with mercury.

\section{Filling with Mercury}

The absolute purity of the mercury used in these experiments is not known, but chemical analysis of representative samples yielded no metallic contaminants present above the detection limit (typically 50-100 ppb) except for silver ( $85 \mathrm{ppb}$ ) and silicon (about 100 $\mathrm{ppb).} \mathrm{No} \mathrm{gas} \mathrm{analysis} \mathrm{was} \mathrm{performed.} \mathrm{(Prior} \mathrm{to} \mathrm{use} \mathrm{in} \mathrm{these} \mathrm{experiments,} \mathrm{the} \mathrm{mercury} \mathrm{was}$ stored in sealed steel containers under a small amount of air for many years.) Immediately prior to use in these loops, the mercury was poured through cheesecloth to remove the small amount of debris (oxides) floating like a sheen on top of the mercury. Following this "filtering" the mercury appeared very shiny and free of floating debris.

Loop \#1 was alternately evacuated (internal pressure a few microns of mercury) and filled with helium several times. Subsequently, the loop was evacuated and filled with mercury from the reservoir at the top (the ullage of which was also evacuated/purged with helium). Approximately one atmosphere of stagnant helium was used as a cover gas for the mercury in the loop. The loop was warmed to near operating temperature and the excess mercury (expanded above fill line at room temperature) was drained off through a side arm of the loop. 
Loop \#2 was similarly filled with mercury $(\mathrm{Hg})$ to which $1000 \mathrm{wppm}$ of gallium (Ga) had been added. The required amount of $\mathrm{Ga}$ was added (in the form of small chips) directly into the loop (via opening at the top of the cold leg). The loop was subsequently evacuated and backfilled with helium several times to remove as much air (oxygen) as practical, finishing with the loop in the evacuated state. Using heat tape, the reservoir of $\mathrm{Hg}$ (on top of hot leg) was heated to about $100^{\circ} \mathrm{C}$, as were the heated portions of the loop. The warm $\mathrm{Hg}$ was then allowed to drain into the evacuated loop. All valves were allowed to remain open for a few hours (to permit communication between the entire volume of $\mathrm{Hg}$ and the dissolved $\mathrm{Ga}$ ) while a low temperature gradient was established in the loop to encourage mixing of the $\mathrm{Ga}$ in the entire $\mathrm{Hg}$ volume. After a few hours, the loop was raised to operating temperature and excess $\mathrm{Hg} / \mathrm{Ga}$ drained from the side arm.

\section{Loop Operation}

Clamshell-type furnaces were placed on the vertical hot leg (2) and on the nearhorizontal lower portion of the loop (1). The control temperature of the lower furnace was kept somewhat below the temperature of those on the vertical hot leg to help maintain the mercury flow pattern. The vertical section of each cold leg was cooled by compressed air delivered from three roughly equi-spaced copper tubes with outlets placed close to the outer loop surface. After a few days of furnace and airflow adjustments, each loop was "stabilized" such that the temperature of the mercury at each thermocouple position became constant within about $\pm 2^{\circ} \mathrm{C}$. Loop \#1 was operated without interruption for $4760 \mathrm{~h}$ and Loop \#2 was operated without interruption for $5000 \mathrm{~h}$ at the nominal temperatures given in Table 2.

The flow rate of the mercury inside the loop was determined using a localized "temperature spike" test. In this procedure, a propane torch was used to heat a small area in the middle of the roughly horizontal section at the top of the loop for about 15 seconds. 
The time required for the resultant temperature "spike" to reach each thermocouple in sequence around the loop along with the distance between thermocouples was used to estimate the velocity of the mercury. The mercury flow rate along the tubing axis was found to be approximately constant at $1.0 \mathrm{~m} / \mathrm{min}$ in each loop over the duration of the experiment.

Table 2. Nominal temperatures at each "corner" of the thermal convection loops. Strip chart print out of temperatures for each thermocouple indicate $+1-2^{\circ} \mathrm{C}$ drift over the duration of the experiment at each location.

$\begin{array}{cc}\text { Bottom of hot leg } & 268^{\circ} \mathrm{C} \\ \text { Top of hot leg } & 305^{\circ} \mathrm{C} \\ \text { Top of cold leg } & 280^{\circ} \mathrm{C} \\ \text { Bottom of cold leg } & 242^{\circ} \mathrm{C} \\ & \\ \text { Nominal temperature gradient } & 63^{\circ} \mathrm{C}\end{array}$

\section{RESULTS}

\section{Loop \#1}

This loop was terminated after $4760 \mathrm{~h}$ of uninterrupted operation. After about an hour of cooling, the mercury was drained from the loop via the valve near the bottom of the cold leg. The post-test mercury appeared very bright and shiny (as when it was poured into the loop). However, entrained with the last few milliliters of mercury drained from the loop was a small amount (approximately one gram) of dull, olive green/gray powder, which had apparently been floating on the top of the mercury. Analysis of the green/gray powder is discussed in a subsequent paragraph.

Handling as gently as possible, the loop was subsequently cut (dry, using a tubing cutter and a jeweler's saw) in strategic locations to free the coupon chains in each of the 
vertical legs. At least small portions of each specimen from the hot leg exhibited residual adherent mercury, and the coupons appeared generally darker in color/luster compared to unexposed coupons. In the cold leg, residual mercury was observed adhering to the surfaces of the coupons on the top two-thirds of the chain and, similar to the hot leg coupons, these coupons also had a somewhat darkened luster. However, the coupons at the bottom of the cold leg (essentially the lowest 12 , a specific demarcation was not obvious), were relatively free of adherent mercury and appeared relatively shiny compared to the other coupons exposed in this loop.

Loop tube sections were cut open longitudinally, and these revealed largely smooth surfaces with only minor areas with adherent mercury. Based on visual assessment, the tube walls appeared generally more shiny with less adherent mercury compared to the coupons of corresponding position.

To prepare for photography and reweighing, all of the coupons were wiped, ultrasonically cleaned in acetone (about $1 \mathrm{~h}$ ), and dried in a jet of air. Figure 4 shows the 32 hot leg coupons - following cleaning - arranged in order of descending position. The surfaces all show some darkening compared to the luster of unexposed coupons, although there are small areas/spots of much brighter luster on some coupons. Figure 5 similarly shows the 32 cold leg coupons following cleaning. Note that the bottom 12 or 13 coupons (those exposed at the lowest temperature) exhibit mostly a shiny luster compared to a much darker luster on coupons closer to the top. 


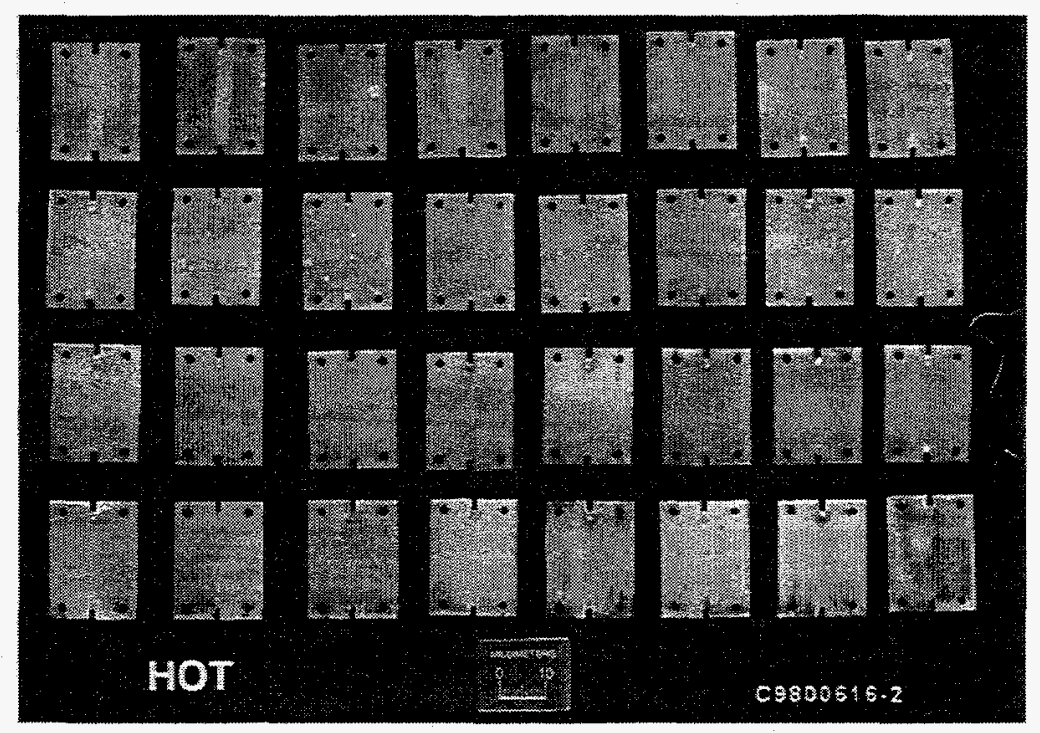

Fig. 4. 316L SS coupons exposed in the hot leg of loop \#1. Coupons $1-8$ in the top row, $9-16$ in the second row, etc.

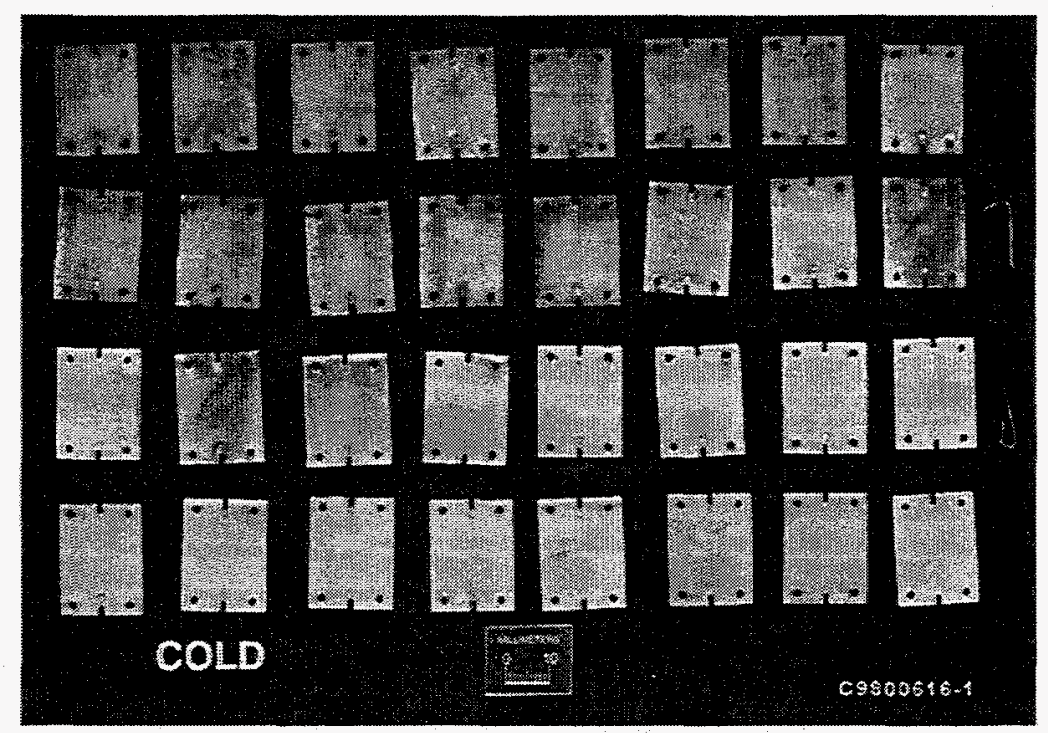

Fig. 5. 316L SS coupons exposed in the cold leg of loop 1 . Coupons $1-8$ in top tow, $9-16$ in second row, etc.

Weight change as a function of position (temperature) is shown in Fig. 6 .

Temperature at each coupon position was estimated by assuming a linear temperature 
variation between thermocouples at the top and bottom of the coupon rack. The maximum weight loss (coupon at the top of the hot leg, temperature $305^{\circ} \mathrm{C}$ ) corresponds to a uniform general corrosion of about $3.8 \mu \mathrm{m} / \mathrm{y}$ (or about $2.1 \mu \mathrm{m}$ of uniform surface removal) over the duration of the loop exposure. With only minor scatter, weight loss is a smooth and regular function of temperature until the temperature becomes so low that apparently no corrosion (no wetting) of $316 \mathrm{~L}$ occurs in mercury.

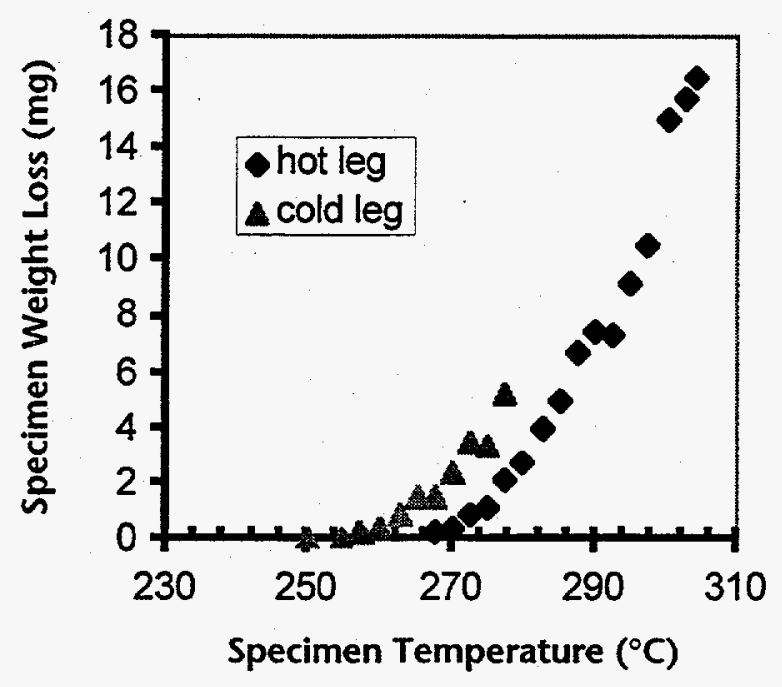

Fig. 6. Specimen weight loss as a function of temperature (position) in loop \#1.

Representative coupons were mounted in cross section for standard metallographic preparation. Figure 7 is representative of the coupon from the top of the hot leg (temperature $305^{\circ} \mathrm{C}$ ). In the as-polished condition, it reveals a shallow "reaction zone" at the specimen surface which appears to be significantly altered from the composition/structure of the base material. This affected region is relatively uniform in appearance (porosity) and depth (average is about $9-10 \mu \mathrm{m}$, maximum is about $12 \mu \mathrm{m}$ ) on all exposed surfaces of the coupon. When viewed in the metallographically etched condition, the reaction zone appears to advance preferentially along grain boundaries as indicated in Fig. 8. 


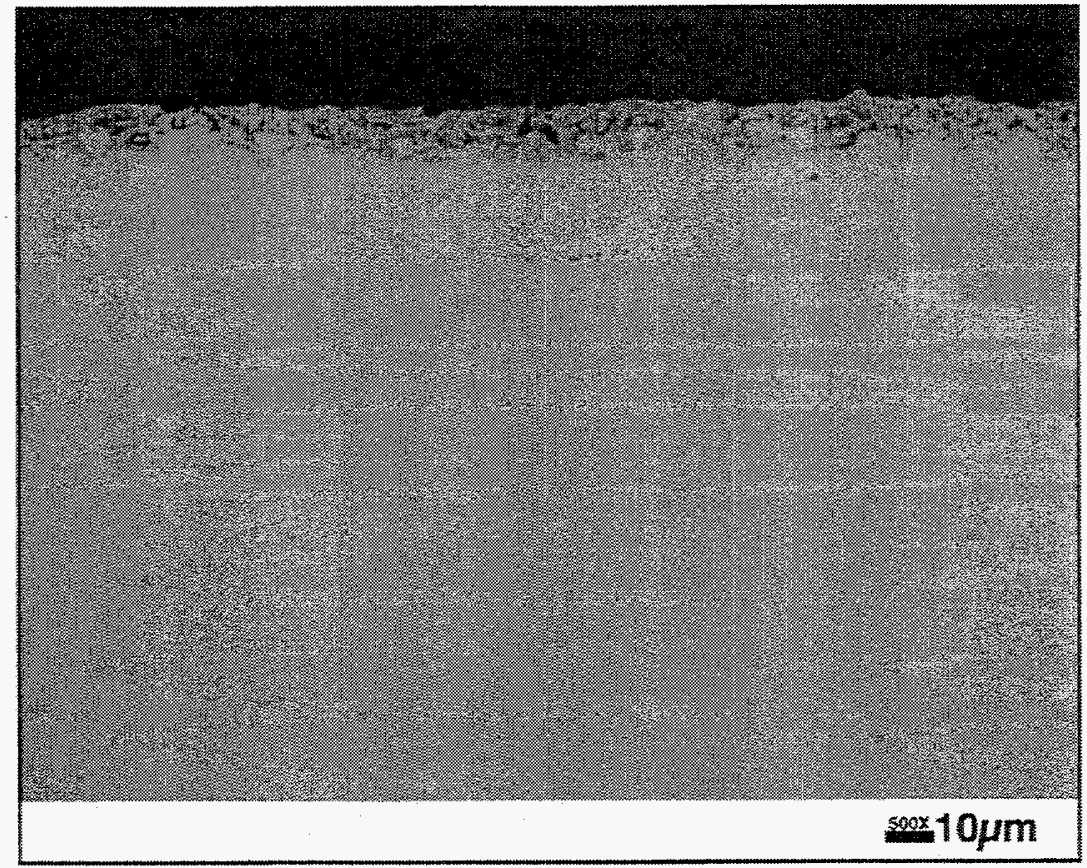

Fig. 7. As-polished cross section of 316L SS specimen from the top of the hot leg $\left(305^{\circ} \mathrm{C}\right)$ in loop $\# 1$ [98-1797-01].

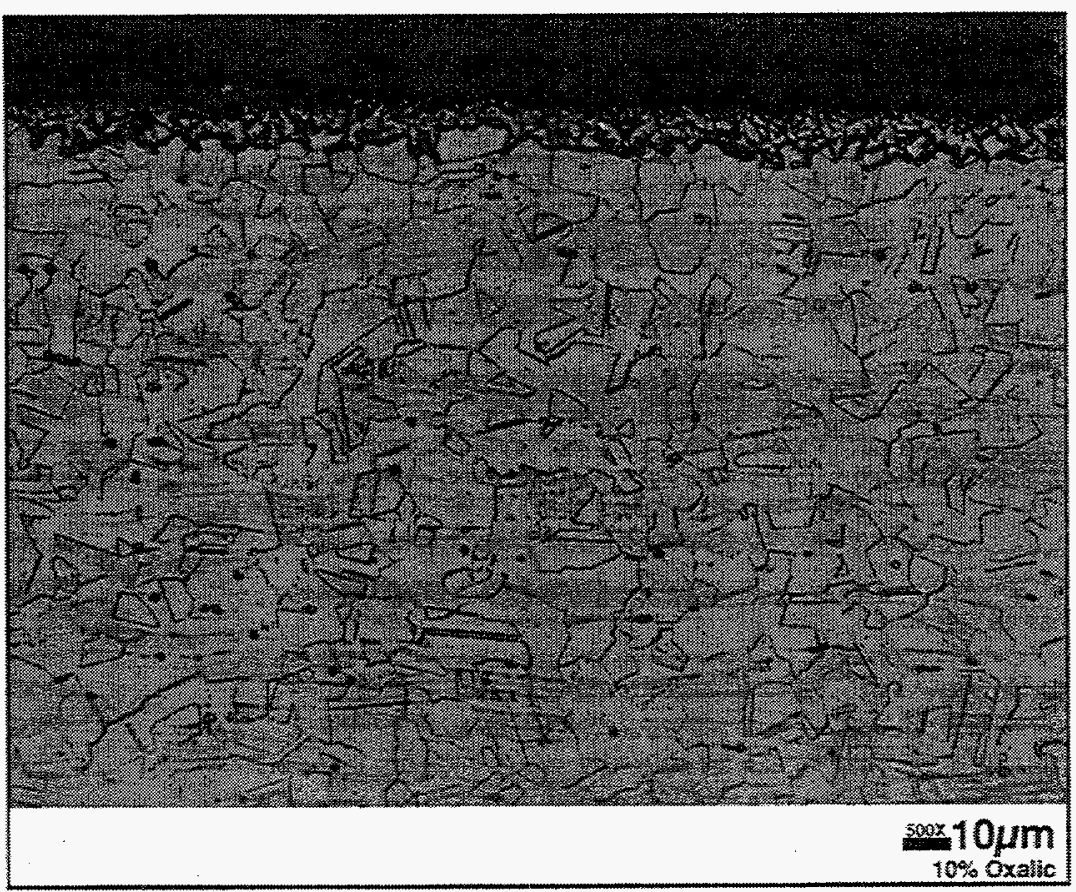

Fig. 8. Etched (10\% oxalic acid, electrolytic) cross section of $316 \mathrm{~L}$ SS specimen from the top of the hot leg $\left(305^{\circ} \mathrm{C}\right.$ ) in loop $\# 1$ [97-1797-04]. 
A similar region of attack was observed on the surface of the coupon from the middle of the hot leg (temperature $288^{\circ} \mathrm{C}$ ). Corresponding to lesser weight loss, however, the corroded layer is much thinner on (average 4-6 $\mu \mathrm{m}$ ) on this coupon. Near the bottom of the hot leg (temperature $275^{\circ} \mathrm{C}$ ), the reaction zone is barely perceptible $(1-2 \mu \mathrm{m}$ thick) at $500 \mathrm{X}$. At the top of the cold leg $\left(280^{\circ} \mathrm{C}\right)$, the reaction zone appears similar to that from the middle of the hot leg at a similar temperature. At the bottom of the cold leg $\left(242^{\circ} \mathrm{C}\right)$, no reaction zone is evident and no deposit of any type was observed. Only the original coupon surface roughness is apparent (representative metallography in Fig. 9).

Figure 10 shows a backscattered electron image of the as-polished cross section of the specimen from the top of the hot $\operatorname{leg}\left(305^{\circ} \mathrm{C}\right)$. This photo reveals the surface to be very porous and that the pores are apparently connected (open) in the three-dimensional matrix. The light colored particles within the attacked area were identified by microprobe analysis to be tiny beads of mercury (apparently resistant to specimen cleaning efforts). [In fact, during prolonged exposure in the scanning electron microscope (SEM) vacuum chamber, a small bead of $\mathrm{Hg}$ was observed to be drawn to the surface of the specimen.]

Microprobe chemical analyses were performed at a number of locations across the "corroded" region and into the base material. The "corroded" region was found to be completely depleted of $\mathrm{Ni}$ and about $70 \%$ depleted of $\mathrm{Cr}$. While present in a smaller overall amount, the Mo concentration in the reaction zone was not significantly different from that in the bulk material. 


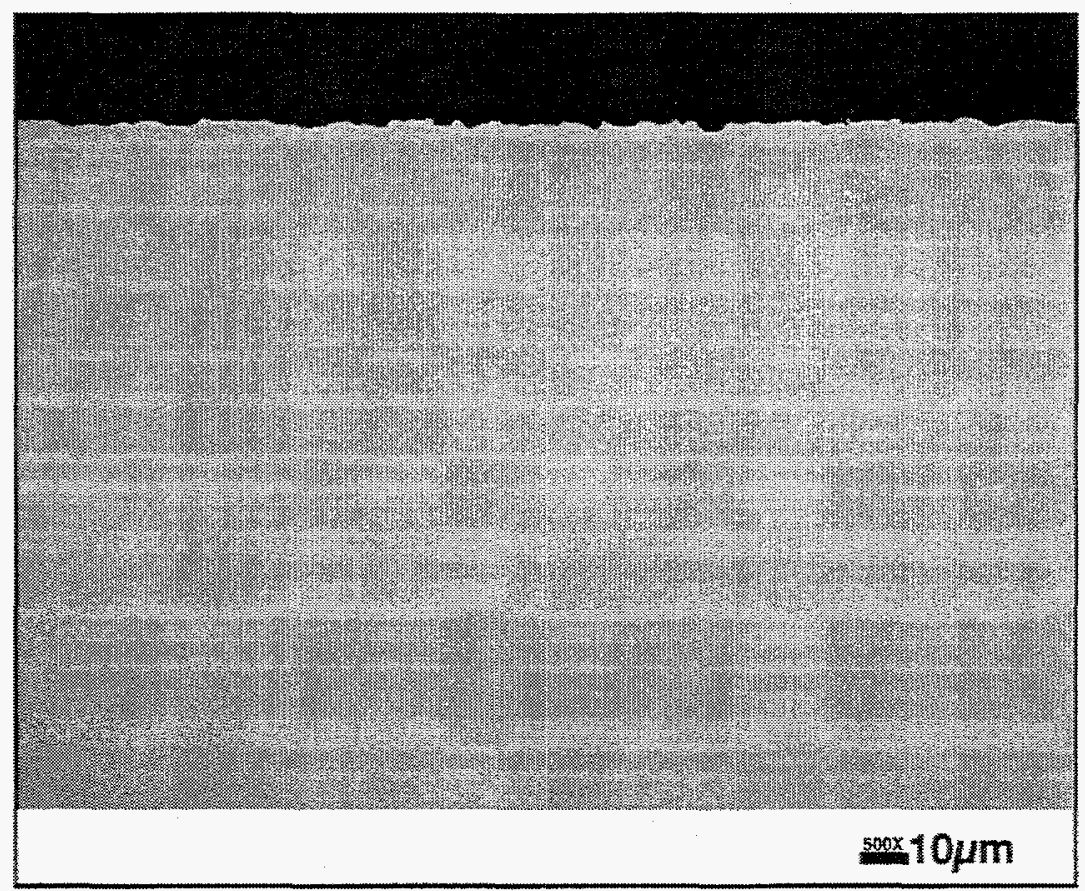

Fig. 9. As-polished cross section of unexposed 316L SS specimen [98-0028-03].

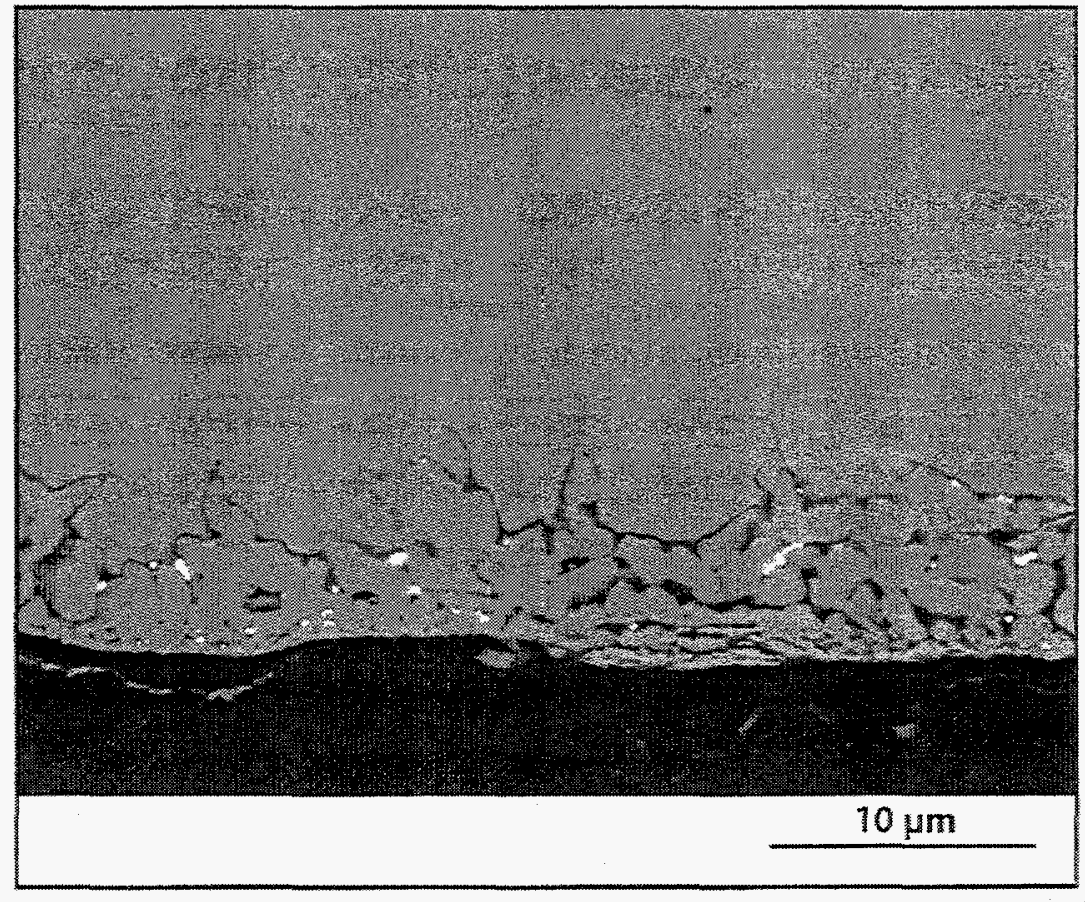

Fig. 10. Backscattered electron image of as-polished cross section of $316 \mathrm{~L}$ SS specimen from top of hot leg $\left(305^{\circ} \mathrm{C}\right)$ in loop $\left.1 \mathrm{EAK}-4818\right]$. 
The composition gradient at the interface between the depleted surface material and the adjacent substrate (and bulk) material is very steep. A representative microprobe scan is shown in Fig. 11 along with the area from which the microprobe data was collected. The scans compare the elemental concentrations in material just barely on the liquid metal side of the reaction zone interface (spot centered $6.8 \mu \mathrm{m}$ from the outer surface) with material just barely on the bulk-side of this interface (spot centered $8.3 \mu \mathrm{m}$ from the outer surface). Further microprobe analyses revealed the composition of the "corroded" region to be the same everywhere, and the composition of material just barely on the bulk side of the reaction zone interface matched that of the stainless steel very far removed from the interface.

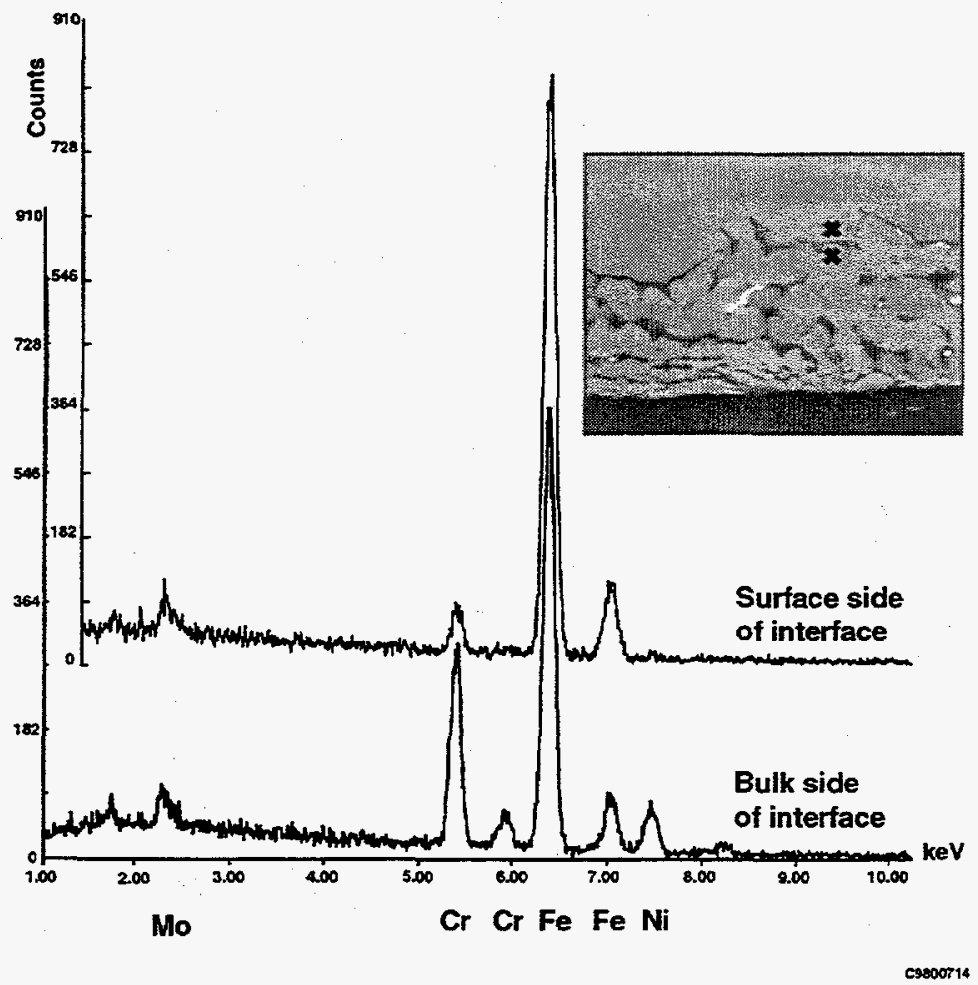

Fig. 11. Representative microprobe data from $316 \mathrm{~L}$ specimen from the top of the hot leg $\left(305^{\circ} \mathrm{C}\right)$ in loop \#1. Note that peak associated with nickel is absent from the scan on corroded material and the peaks associated with chromium are significantly reduced. 
Coupons from other locations in the loop were also examined with the microprobe. The composition of the "corroded" region appears essentially independent of the loop/Hg temperature and layer thickness. No "corroded" region was detected on coupons from the bottom-most portion of the cold leg.

Rutherford backscattering (RBS) analysis was also performed on a limited number of coupon surfaces. Analysis was made directly on the exposed sample surface as opposed to a cross section mounted in epoxy. The activation volume of the analysis technique includes a hemisphere of radius about $0.5 \mu \mathrm{m}$. Consistent with the microprobe results, RBS revealed that the extreme outer surface of coupons exhibiting the reaction zone is severely depleted in nickel and chromium.

The green/gray powder that was collected from the residual mercury drained from the loop was analyzed by $x$-ray diffraction. The diffraction pattern indicated the powder was primarily amorphous in nature and contained substantial $\mathrm{Hg}$. Computer processing and analysis techniques were used to separate the small crystalline component of the pattern, and the results indicate that the crystalline component of the powder is primarily $\mathrm{NiO}$ with some amount of $(\mathrm{Cr}, \mathrm{Fe})_{2} \mathrm{O}_{3}$. In addition, a small amount of $\mathrm{HgCl}$ is suspected to be in the reaction product.

A Ferritescope (Fischer model \#MP3C), typically used for measurement of ferrite content in an austenitic stainless steel weld, was used to confirm transformation to the ferrite phase at the surface of the exposed coupons. Semi-quantitative results correlating the magnetic response of the surface with the weight loss of the individual coupons are shown in 
Fig. 12. Specimens of the loop tubing were also cut for metallographic analysis. No attack (reaction zone) was detected on the tube ID at any position around the loop.

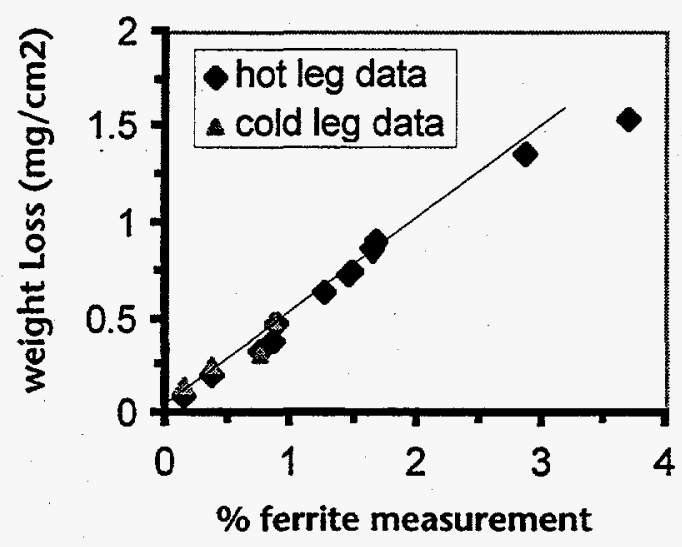

Fig. 12. Relationship of surface ferrite measurement and coupon weight loss in loop \#1.

\section{$\underline{\text { Loop \#2 }}$}

This loop was terminated after $5000 \mathrm{~h}$ of uninterrupted operation. When the $\mathrm{Hg}$ with 1000 wppm Ga was drained from this loop, it was initially very shiny. After a few moments of exposure to room air, however, the $\mathrm{Hg} / \mathrm{Ga}$ mixture began to form a dark gray scum that floated on the mixture surface and aggressively clung to the glass beaker surfaces in which it was contained. Unlike Loop \#1, no green/gray powder material was observed among the last few milliliters of material drained from the loop.

When the coupons were removed from this loop, they were found to be uniformly very shiny (no dull luster like many specimens removed from Loop \#1) and no trace of $\mathrm{Hg} / \mathrm{Ga}$ was observed (with the unaided eye) adhering to the coupons. As before, specimens were also cut from the loop walls. Like the coupons from this loop, they were found to be very shiny and apparently not wet by the $\mathrm{Hg} / \mathrm{Ga}$ mixture. 
During initial cleaning, it was apparent there was little $\mathrm{Hg} / \mathrm{Ga}$ or corrosion product(s) to be removed from the specimens. After cleaning, none of the specimens were found to have a detectable weight change compared to the initial coupon weights (measured to \pm $0.00002 \mathrm{~g}$ on specimens with $10.6 \mathrm{~cm}^{2}$ of exposed area).

Metallographic analysis confirmed the absence of any attack or deposit on coupons exposed in Loop \#2. No "corroded" layer was observed on coupons from either leg of the loop or on specimens taken from the loop walls. Similarly, no deposit was observed in either location. The specimens appeared unchanged from the original slight surface roughness. Microprobe analysis and other techniques failed to detect more than trace $\mathrm{Hg}$ or $\mathrm{Ga}$ on the surfaces of the specimens. No ferromagnetic potential was detected on any of the $316 \mathrm{~L}$ SS surfaces exposed in Loop \#2.

\section{DISCUSSION}

Wetting (or lack thereof) is clearly a dominant factor in the corrosion of the $316 \mathrm{~L}$ SS TCLs and specimens. In Loop \#1 (pure Hg only), the 316L SS specimens were apparently wet by the liquid mercury at temperatures above about $255^{\circ} \mathrm{C}$. This was evidenced by the specimen appearance (development of a dull luster rather than shiny appearance), post-test examination revealing at least small amounts of somewhat adherent mercury on the specimens exposed above this temperature, and the weight losses and metallographic changes on coupons exposed above this temperature. Metallographic and microanalytical examination revealed a shallow reaction zone in $316 \mathrm{~L}$ SS in $\mathrm{Hg}$ at these temperatures exhibiting substantial $\mathrm{Ni}$ and $\mathrm{Cr}$ leaching from the exposed surfaces leading to significant porosity and transformation of the "corroded material" to ferrite. Similar porous layers 
associated with selective dissolution of $\mathrm{Ni}$ and $\mathrm{Cr}$ have been observed for type $316 \mathrm{SS}$ in $\mathrm{Li}$ $[6,7]$ and $\mathrm{Pb}-17 \% \mathrm{Li}[8,9]$.

The extent of porosity in the reaction zone was roughly estimated from SEM photographs of the surface attack by using a graph paper overlay and summing the pore area in the entire "corroded" zone defined by the width of the photograph and the deepest extent of attack. Using this procedure for the greatest average reaction zone thickness (Fig. 10, deepest attack $9 \mu \mathrm{m}$ in this view), the pore area of the corroded zone was estimated to be $23 \%$ for the coupon from the top of the hot leg. This value is significant in that $23 \%$ of the attacked volume of $316 \mathrm{~L}$ corresponds to a mass loss of $0.017 \mathrm{~g}$ for the $316 \mathrm{~L}$ coupon at this position, and the actual measured weight loss was $0.015 \mathrm{~g}$. The loss of essentially $100 \%$ of the $\mathrm{Ni}$ and about $75 \%$ of the $\mathrm{Cr}$ which have been leached from the surface layer, as shown by the microprobe analyses, is also consistent with a loss of about $22 \%$ of the base material. [As expected, then, the extent of metallographic attack $(9-10 \mu \mathrm{m})$ should be $4-5$ times that predicted by uniform weight loss $(2.1 \mu \mathrm{m})$.] Taken together, these results indicate that $\mathrm{Ni}$ and $\mathrm{Cr}$ leaching account for the total porosity, and mass loss of Fe from the $316 \mathrm{~L}$ SS is not participating in the corrosion process in a significant way. This conclusion assumes that the small amount of mercury found in the surface layer pores did not contribute significantly to the weight change measurement. It also assumes that the coupon dimensions are not changing during the exposure and that the volume of ferrite layer (including porosity) is equivalent to the parent austenite volume. Although none of the coupons (including those experiencing the greatest extent of corrosion) exhibited a measurable thickness change, the thickness tolerance of a coupon is about \pm 25 or $30 \mu \mathrm{m}$, as is the ability to measure coupon thickness, so any change in actual thickness would be below the measurement threshold. 
Neither the ferrite on the surface of the corroded specimens nor the austenite immediately adjacent to the ferrite reveals a composition gradient. Although only one data point from the end of exposure time at each temperature is available, the absence of a concentration gradient in the parent stainless steel substrate (adjacent to the ferrite) indicates the rate limiting step for the leaching reaction is not solid state diffusion ( $\mathrm{Ni}$ and $\mathrm{Cr}$ ) in the austenite. Similarly, the absence of a composition gradient in the ferrite indicates the layer itself is not a substantial barrier to further leaching. Potentially, the phase transformation could accelerate the transport of $\mathrm{Ni}$ and $\mathrm{Cr}$ at the ferrite/austenite phase boundary. Furthermore, the open porosity in the ferrite layer may provide mercury "channels" that also act to decrease diffusion distances considerably.

One possible effect of radiation (high dpa) in austenitic stainless steels is radiationenhanced diffusion of nickel [10,11]. Potentially, this factor could increase availability/leaching of $\mathrm{Ni}$ into the $\mathrm{Hg}$ in the actual SNS target compared to the $\mathrm{TCL}$ exposures. This is not expected to be a large factor, as the distances over which enhanced diffusion might occur are small. Other factors - such as the influence of radiation and radiation products on wetting and the mechanism by which $\mathrm{Ni}$ is rejected from solution in the $\mathrm{Hg}$ - could also have an influence.

Because the transformation to ferrite generates a magnetic phase (parent austenite is not magnetic), the magnetic response of the target containment surface could potentially be used as a non-destructive test to estimate the extent of corrosion. A correlation of magnetic response of the surface with coupon weight loss appears in Fig. 12. The magnetic response of the corroded $316 \mathrm{~L}$ SS surface correlates closely with the extent of weight loss and metallographic attack. 
Coupons (or TCL walls) exposed at temperatures below about $255^{\circ} \mathrm{C}$ did not reveal any signs of attack (no change in coupon luster, no ferrite development, no weight change - loss or gain) and, below this same temperature, no wetting of the coupons apparently occurred. The solid material found floating on top of the $\mathrm{Hg}$ at the termination of Loop \#1 may represent material dissolved from interaction of $\mathrm{Hg}$ and coupons at temperature above $255^{\circ} \mathrm{C}$, and rejected from solution in the cold part of the TCL. If wetting had developed in the colder portions of the loop, this material presumably would have been deposited on the cold leg surfaces. However, the absence of wetting at relatively low temperatures may have prohibited deposition in favor of simple precipitation from solution due to supersaturation. This result has implications for the operation of the SNS in that it suggests deposition of corrosion products in the cold portions of the SNS is unlikely without treatments designed to increase wetting of the containment surface. Further, some type of skimming/filtering may be useful to maintain the cleanliness of the target mercury, although removal of corrosion products could enhance the dissolution process.

An important consideration in evaluating these results is the observation that the TCL tube walls (both loops) did not appear wetted or attacked at any position around the loop. This is somewhat confounding, particularly for Loop \#1, in light of the fact that the loop walls act as a heat transfer surface and are therefore at a slightly higher temperature than the corresponding hot leg specimens inside the loop (which showed attack and, presumably, wetting). Presently, it is suspected that the steam cleaning procedure employed on the loops after fabrication was not as effective as the cotton swab wipe test might have suggested, and that a residual film of some type inhibited wetting and, therefore, corrosion. Another possibility, of course, is that the steam treatment itself led to the development of a very wetting-resistant oxide/hydroxide on the tube walls. 
The velocity of the liquid metal was very reproducibly found to be $1 \mathrm{~m} / \mathrm{min}$ (3.3 ft/min) in both TCLs via the "temperature spike" test. The temperature spike routinely persisted one complete circuit of the loop and occasionally somewhat farther. Another reproducible observation associated with this test was a temperature decrease at each thermocouple preceding the temperature increase associated with the moving hot spot. It is suspected that the introduction of a significant localized heat flux for the temperature spike test temporarily slows or even stops the flow of liquid metal in the loop. As a result of the flow disruption, the liquid metal preceding the hot spot around the loop flow direction is exposed to increased cooling time in the cold leg. Thus, the introduction of a hot spot simultaneously creates a "cold spot" slightly ahead of it.

Clearly, the "temperature spike" test is not necessarily a very precise method to determine flow rate in these TCLs. In particular, it was routinely observed that increasing distance around the loop tended to obscure the precise time (and peak height) associated with the arrival temperature spike at each thermocouple. In view of the high thermal conductivity and relatively slow-moving fluid, this complication is not unexpected.

Accordingly, to further confirm the approximate flow velocity in the TCLs, a crude heat balance was performed on the hot leg. This was accomplished by calculating the mass velocity of $\mathrm{Hg}$ that would undergo a temperature increase from $\mathrm{T} 1$ (bottom of hot leg) to $\mathrm{T} 2$ (top of hot leg) on application of a known power input passing through the hot leg. Mathematically,

(mass Hg) $\times$ (average heat capacity) $\times(\mathrm{T} 2-\mathrm{T} 1)=$ (power input) $\times$ (heating time) 
where heating time is the residence time of the flowing $\mathrm{Hg}$ as it rises from $\mathrm{T} 1$ to $\mathrm{T} 2$, and

(mass $\mathrm{Hg}) /($ heating time) $=$ mass velocity

The total heat input to the hot leg between the thermocouples was measured (volts, amps, and fraction of furnace time in "on" mode are all known) and the average heat capacity of $\mathrm{Hg}$ between $\mathrm{T} 1$ and $\mathrm{T} 2$ determined from a standard handbook. The TCLs described here were not instrumented for estimating heat losses, but Glatron and Wood [12] calculated a power efficiency of about $70 \%$ considering convective and radiative losses in a similar size/shape/insulated TCL containing molten salts. (The conduction losses along the vertical length of the hot leg were not included, but these may be significant for a slow moving liquid of high thermal conductivity such as $\mathrm{Hg}$.) The mass velocity in Eqn. 2 can be correlated to linear velocity as follows:

mass velocity $=$ (tube cross section area) $\mathrm{x}(\mathrm{Hg}$ density) $\mathrm{x}$ (velocity of $\mathrm{Hg}$ )

In this manner, the velocity of $\mathrm{Hg}$ in the TCLs was estimated to be about $1.8 \mathrm{~m} / \mathrm{min}$. In view of the very approximate estimate of heat loss due to convection and radiation for this specific experimental arrangement and the fact that conduction losses along the hot leg have not been included, this is considered acceptable confirmation of the "temperature spike" method to determine flow velocity.

Compared to the flow rate expected in the SNS target (order of $1 \mathrm{~m} / \mathrm{s}$ ), the flow rate developed in the TCLs described here $(1 \mathrm{~m} / \mathrm{min})$ is relatively small. Velocity effects could be 
significant if the rate controlling step in liquid $\mathrm{Hg}$ corrosion of the target containment (316L SS or any other material) is the rate at which boundary layer solute is moved to the bulk liquid, as discussed below.

For simple solution of metals/alloys in a liquid metal, the rate of mass loss (corrosion rate) can be described as

mass flux into solution $=$ (rate constant $) \times$ (solubility driving force $)$

Epstein [2] postulated that the rate constant for this process falls in to one of two major categories. [His analysis did not consider the case of solid-state diffusion controlled mass transfer; however, previous discussion herein indicates diffusion of $\mathrm{Ni}$ and $\mathrm{Cr}$ in the austenite or ferrite does not appear to be rate-limiting.] In one case, the rate constant is related to the diffusion coefficient of the dissolved species in the liquid. In such a case, solute atoms rapidly enter the liquid at the solid/liquid interface and tend to saturate the boundary layer with solute. The rate controlling step for the process then becomes how quickly the solute atoms can diffuse from the saturated boundary layer into the bulk solution to encourage further dissolution. In this case, the rate constant is expected to be dependent on the liquid velocity (actually Reynolds number), as velocity influences the thickness of the boundary layer and thus the diffusion distance and mixing into the bulk. The contrasting case assumes that transfer of the solute to the solid/liquid boundary and/or transport across the solid/liquid boundary is the rate limiting step in the solution process. In such a case, saturation of the boundary layer is not a factor and thus this mechanism tends to be relatively independent of liquid velocity. 
Reaction rates for processes involving an activation energy, such as diffusion, are described by an Arrhenius type of equation, typically of the form

$$
\mathrm{K}=\mathrm{k}_{0} \exp (-\mathrm{Q} / \mathrm{RT})
$$

where $k_{0}$ is a constant, $R$ is the gas constant, $T$ is absolute temperature, and $Q$ is the activation energy for the rate-controlling step of the process. In the case of liquid diffusion or reaction-rate controlled processes, the solubility driving force (Eqn. 4 ) is the difference in the equilibrium solute concentration at the solid/liquid interface $\left(\mathrm{C}_{\text {sat }}\right)$ and the bulk solute concentration $\left(\mathrm{C}_{\text {bulk }}\right)$. Along with the rate constant, $\mathrm{k}, \mathrm{C}_{\text {sat }}$ is itself a function of temperature as

$$
\mathrm{C}_{\mathrm{sat}}=\mathrm{k}_{\mathrm{l}} \exp (-\Delta \mathrm{H} / \mathrm{RT})
$$

where $k_{1}$ is a constant, $R$ and $T$ are as in Eqn. 5, and $\Delta H$ is the heat of solution for the corroding element.

For the liquid diffusion controlled case, Epstein [2] develops a number of equations describing the dynamic corrosion rate (noting many parallels to heat transfer calculations) and, using a number of simplifying assumptions for the case of a saturated boundary layer, concludes that

$$
\mathrm{d} \ln \text { (corrosion rate) } / \mathrm{dT}=\mathrm{Q} / \mathrm{RT}
$$


is an adequate approximation. If this analysis applies to the present data, it follows that a plot of In (corrosion rate) vs $1 / \mathrm{T}$ would yield a straight line with slope $-\mathrm{Q} / \mathrm{R}$. Using this approach, the plot in Fig. 13 was developed. A straight line fits the data well with the exception of the lowest temperatures of the hot leg. The slope of the line in Fig. 13 suggests an activation energy for the rate limiting step in the corrosion/dissolution process of about $3 \mathrm{~kJ} / \mathrm{mol}$.

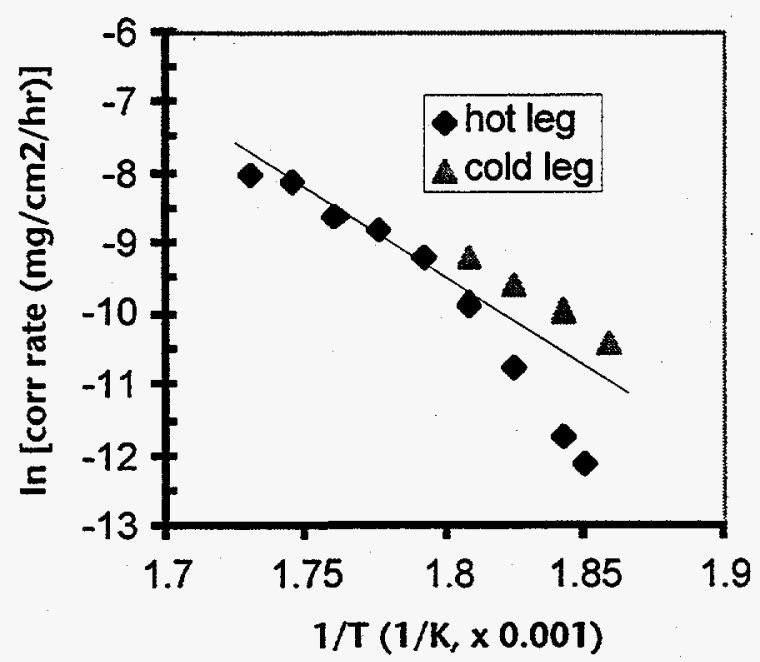

Fig. 13. Analysis of weight loss data following the approach of Epstein [2].

Tortorelli and DeVan [6] used a somewhat more complex treatment, taken largely from Holman [13], to derive a relationship to analyze corrosion rate as a function of temperature for a TCL. They used the concept that the corrosion rate (CR) could be described as

$$
C R=(\text { rate constant }) \times\left(\mathrm{dC}_{\mathrm{sat}} / \mathrm{dT}\right) \times(\Delta \mathrm{T})
$$


for cases in which the rate constant and the variation in $\Delta \mathrm{H}$ were small over the temperature range of interest. Here, $\Delta T$ is the temperature difference between the temperature of interest and the temperature at the point in the hot leg where the corrosion rate is zero. Using Eqn. 8 in conjunction with expressions similar to Eqn. 5 and Eqn. 6, the expression

$$
\ln \left[\mathrm{CR} \times \mathrm{T}^{2} / \Delta \mathrm{T}\right]=\ln [\mathrm{kA} \Delta \mathrm{H} / \mathrm{R}]-(\mathrm{Q}+\Delta \mathrm{H}) / \mathrm{RT}
$$

was derived. If this treatment describes the process, a plot of $\ln \left[\mathrm{CR} \times \mathrm{T}^{2} / \Delta \mathrm{T}\right]$ against $1 / \mathrm{T}$ should yield a straight line from which the sum of the activation energy and $\Delta \mathrm{H}$ for solution can be determined. The present data for Loop \#1 were analyzed in this fashion and the result is shown in Fig. 14. Again, a line fits the relatively high temperature data best. In this case, the sum of the activation energy and heat of solution for this approach was calculated to be approximately $2 \mathrm{~kJ} / \mathrm{mol}$.

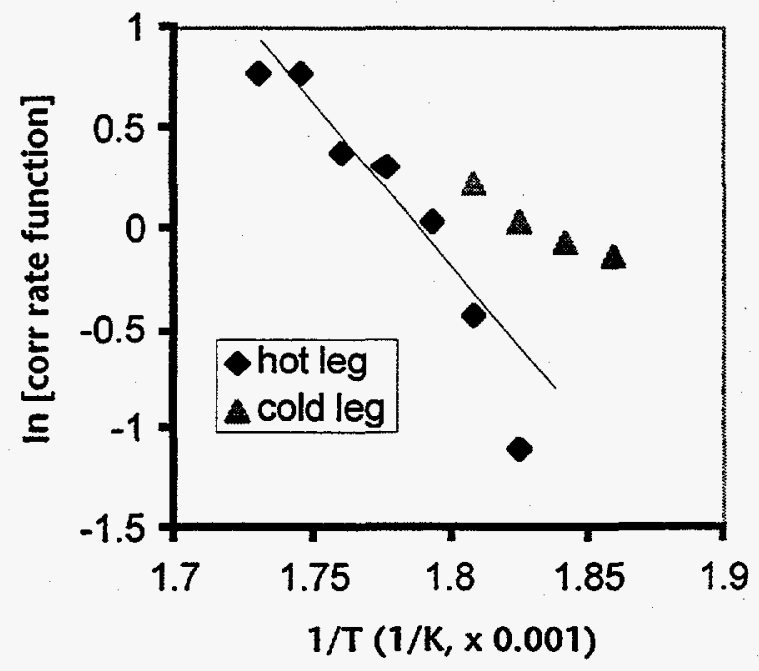

Fig. 14. Analysis of weight loss data following the approach of Tortorelli and DeVan [7]. 
Both approaches assume that corrosion rates have reached a steady state (i.e., are constant with time). However, the data here represent only end-of-test and may not identically represent steady state. Another source of error is the observation that the porous surface, despite cleaning efforts, tends to hold tiny amounts of $\mathrm{Hg}$ which could distort weight loss measurements. In addition, the temperature at each coupon position is not precisely known. The close (but not precise) agreement of cold leg and hot leg coupon weight loss at equivalent temperature (Fig. 6) suggests only a small uncertainty in the temperature. [One of the subtleties of the results here is that, all other things equal, one might expect the weight loss of the hot leg coupons to actually be slightly greater than that for the cold leg coupons at the same temperature. In principle, mercury in the hot leg is picking up solute $\left(\mathrm{C}_{\text {bulk }}\right.$ is increasing) as the mercury moves toward the cold leg. In the cold leg, solute concentration apparently occurs by rejection of solute from mercury as a function of decreasing temperature. However, it seems reasonable to postulate that some amount of "supercooling" is required to nucleate an insoluble precipitate in the cold leg. Therefore, $\mathrm{C}_{\text {bulk }}$ is slightly higher in the cold leg than in the hot leg at equivalent temperature, and therefore, less corrosion should occur in the cold leg. Figure 6 shows that the cold leg coupons actually reveal slightly greater weight loss. Considering heat conduction along the thermocouple wires, a possible explanation for this minor deviation is that the hot leg thermocouples, being better insulated, tend to read a little high and the cold leg thermocouples, without any insulation, tend to read a little low compared to the actual coupon temperature.] Finally, in the second approach considered, some error is no doubt introduced through the selection of the temperature at which the corrosion rate in the hot leg is zero. In this case, $255^{\circ} \mathrm{C}$ was selected based on the shape of the curve in Fig. 6, although no coupons in the hot leg actually reached a temperature this low. 
Even in consideration of these potential errors, the activation energy for the $\mathrm{Hg} / 316 \mathrm{~L}$ corrosion process determined from both of these treatments is so low that solid state diffusion (solution rate limited corrosion) does not appear to be a factor. Rather, the very low activation energy suggests that a reaction, such as a phase transformation, or liquid state diffusion is controlling.

One possibility for liquid state diffusion control is the situation in which solute atoms ( $\mathrm{Ni}$ and $\mathrm{Cr}$ ) rapidly enter the liquid from the ferrite and tend to saturate the liquid boundary layer with solute. The rate at which the process proceeds is then controlled by the rate at which solute atoms can diffuse from the boundary layer to the bulk liquid. At the initiation of the leaching process (parent austenite or very thin ferrite layer exposed to $\mathrm{Hg}$ ), diffusion distances in the solid are short. At longer times, the ferrite layer becomes thicker and porous, but the mercury in the pores may function to keep the diffusion distances for transport of $\mathrm{Ni}$ and $\mathrm{Cr}$ to the liquid short. However, at some point in the process, the mercury in the pores may become sufficiently occluded from the bulk mercury that bulk velocity has only minimal influence on the boundary layer. In such a case, a low activation energy for the process would be expected but the process would be less dependent on bulk velocity.

The addition of gallium to mercury was intended to promote wetting of the $316 \mathrm{~L}$ SS by mercury. However, the apparent absence of corrosion that resulted in Loop \#2 suggest an inhibition of wetting by gallium. We felt it desirable to perform compatibility tests in which the $\mathrm{Hg}$ readily wets the subject material in order to reveal any corrosion tendency in the target system which will operate at a lower temperature. In particular, it is recognized that actual operating conditions of the SNS may involve factors that tend to cause wetting of the 
containment material (at relatively low temperatures) that can not readily be duplicated in lab tests. For example, in a high radiation field, radiation damage at the containment surface may tend to implant $\mathrm{Hg}$ in the surface or otherwise influence the interaction of the surface with the environment. High stresses, very high cycle fatigue loading, and potential cavitation all may tend to open cracks or create fresh surfaces (no oxide layer) which may be readily wet by $\mathrm{Hg}$. In any case, examination of compatibility under conditions in which wetting by $\mathrm{Hg}$ is achieved represent a "worst case" in terms of corrosion of target materials.

The decision to add gallium to mercury as a potential "enhancement" to wetting was based primarily on the fact that gallium itself is known to be an aggressive liquid metal which wets many different materials. Further, $\mathrm{Ga}$ is at least slightly soluble in $\mathrm{Hg}$ (even at room temperature) which facilitates the physical addition. Subsequent to the initiation of the TCL tests, short term exposure tests in a glove box indicated [5] $\mathrm{Ga}$ additions to $\mathrm{Hg}$ had little or no influence on wetting of stainless steels at temperatures below about $200^{\circ} \mathrm{C}$. However, "inhibition" of wetting due to addition of $1000 \mathrm{wppm}$ of gallium to the mercury and exposure at $300^{\circ} \mathrm{C}$ was not anticipated. Only traces of $\mathrm{Ga}$ were detected on the surfaces of the coupons exposed in Loop \#2, so it is unlikely that the role of $\mathrm{Ga}$ is related to a surface reaction/film. Perhaps $\mathrm{Ga}$ influences the solubility of $\mathrm{Ni}$ and $\mathrm{Cr}$ such that dissolution is retarded, but this possibility has not been investigated. At present, future work in this area includes operation of Inconel ${ }^{\mathrm{TM}} 718$ loops using $\mathrm{Hg}$ and $\mathrm{Hg} / \mathrm{Ga}$ as the working fluids for comparison with the present results. [Inconel ${ }^{\mathrm{TM}} 718$ is presently considered to be an alternate material selection to type $316 \mathrm{~L}$ stainless steel for the target containment.] 


\section{CONCLUSIONS}

Wetting of $316 \mathrm{~L}$ SS in a mercury TCL $\left(\max\right.$ temp $305^{\circ} \mathrm{C}$, min temp $242^{\circ} \mathrm{C}$ ) only occurred above about $255^{\circ} \mathrm{C}$ and only on the "cleanest" surfaces. On wetted specimens, a surface region substantially depleted in $\mathrm{Ni}$ and $\mathrm{Cr}$ formed, leading to transformation of the parent austenitic 316L to ferrite and development of significant porosity at the exposed surface. Iron does not appear to participate significantly in the corrosion/dissolution process(es). Limited analysis of the weight loss data as a function of temperature (position) in the Hg-loop indicates that the rate-controlling step in the $316 \mathrm{~L} / \mathrm{Hg}$ corrosion process has a very low activation energy. The low activation energy process suggests control by solute diffusion in the saturated liquid boundary layer adjacent to the corroding surface as opposed to solid state diffusion of solute to/across the solid/liquid boundary. The latter observation suggests corrosion of the 316L SS target material could be sensitive to $\mathrm{Hg}$ velocity. However,

the pores in the ferrite layer (in which the transport from solid to liquid occurs) may be sufficiently occluded to minimize velocity effects.

The small $\mathrm{Ga}$ addition to the $\mathrm{Hg}$ in a second TCL was expected to enhance wetting and, therefore, corrosion. In fact, no weight change in $316 \mathrm{~L}$ coupons or change in appearance of tube wall specimens was observed. Compared to the Hg-loop, this suggests that the $\mathrm{Ga}$ addition discouraged or inhibited wetting of $316 \mathrm{~L}$ by mercury. 



\section{REFERENCES}

1. L. K. Mansur and H. Ullmaier, compiled Proceedings of the International Workshop on Spallation Materials Technology, CONF-9604151, Oak Ridge, TN, April 23-25, 1996.

2. L. F. Epstein, in Liquid Metals Technology - Part I, F. J. Van Antwerpen, ed., "Static and Dynamic Corrosion and Mass Transfer in Liquid Metal Systems," Chemical Engineering Progress Symposium Series, No. 20, Vol. 53, p.67, 1957.

3. J. R. DiStefano, "A Review of the Compatibility of Containment Materials with Potential Liquid Metal Targets," ORNL/TM-13056, August 1995.

4. J. R. Weeks, "Liquidus Curves and Corrosion of $\mathrm{Fe}, \mathrm{Cr}, \mathrm{Ni}, \mathrm{Co}, \mathrm{V}, \mathrm{Cb}, \mathrm{Ta}, \mathrm{Ti}, \mathrm{Zr}$, in 500-750 ${ }^{\circ} \mathrm{C}$ Mercury," Corrosion, Vol. 23, No. 4, p.98 (1967).

5. J. R. DiStefano, S. J. Pawel, and E. T. Manneschmidt, "Materials Compatibility Studies for the Spallation Neutron Source," ORNL/TM-13675, September 1998.

6. P. F. Tortorelli and J. H. DeVan, "Thermal-Gradient Mass Transfer in LithiumStainless Steel Systems," J. Nucl. Mater., Vol. 85/86, p.289 (1979).

7. P. F. Tortorelli and J. H. DeVan, "Mass Transfer Behavior of a Modified Austenitic Stainless Steel in Lithium," J. Nucl. Mater., Vol. 122/123, p.1258 (1984).

8. P. F. Tortorelli and J. H. DeVan, "Corrosion of Ferrous Alloys Exposed to Thermally Convective Pb-17at\%Li," J. Nucl. Mater., Vol. 141-143, p.592 (1986).

9. H. Tas, et. al., "Mass Transfer in Pure Lithium and Lithium-Lead Dynamic Environments," J. Nucl. Mater., Vol. 141-143, p.571 (1986).

10. E. A. Kenik, “Application of Analytical Electron Microscopy to Radiation Damage Studies," J. Nucl. Mater., Vol. 216, p.157 (1994).

11. S. Watanabe, et. al., "Radiation-Induced Segregation Accompanied by Grain Boundary Migration in Austenitic Stainless Steels," J. Nucl. Mater., Vol. 232, p.113 (1996).

12. C. A. Glatron and P. J. Wood, "Determination of Molten Salt Flow Velocity in a Natural Convection Loop," ORNL-MIT-58, May 1968.

13. W. R. Holman, "Mass Transfer by High Temperature Liquid Sodium," American Standard report AECU-4072 (Oct. 15, 1958). 



\section{ACKNOWLEDGEMENTS}

The authors would like to acknowledge the helpful role of many individuals. J. R. Mayotte and H. F. Longmire performed the specimen metallography. J. D. Hunn (Rutherford backscattering), E. A. Kenik (microprobe analysis), and E. A. Payzant (x-ray diffraction) provided analytical services and interpretations. R. B. Ogle and his staff provided Industrial Hygiene advice and services for controlling mercury exposures. J. H. DeVan and P. F. Tortorelli provided review of the manuscript and helpful discussions. F. C. Stooksbury, K. A. Choudhury, and S. A. Shugart helped prepare the manuscript and figures. 


\section{INTERNAL DISTRIBUTION}

1.

2.

3.

4.

5.

6.

7.

8

9.

10.

11.

12.

13-17. J. R. DiStefano

18. K. Farrell

19. T. A. Gabriel

20. J. R. Haines

21. H. W. Hayden

22. L. L. Horton

23. J. D. Hunn

24. D. T. Ingersoll

25. L. L. Jacobs

26. D. R. Johnson

27. J. O. Johnson

28. A. G. Jordan

29. E. H. Lee

$30 . \quad$ D. C. Lousteau

31. A. T. Lucas
32.

33.

34.

35 .

36.

37.

38

43.

44.

45.

46.

47.

48.

49.

50.

51.

52.

53.

54.

55.

56.

57.

58.

59. Laboratory Records, ORNL-RC

60. Office of Scientific \& Technical Information

E. T. Manneschmidt

L. K. Mansur

T. E. Mason

T. J. McManamy

G. E. Michaels

D. E. Moncton

42. S. J. Pawel

M. J. Rennich

S. L. Schrock

M. Siman-Tov

P. T. Spampianto

C. O. Stevens

C. N. Strawbridge

J. P. Strizak

R. P. Taleyarkhan

C. D. West

J. H. Whealton

D. K. Wilfert

D. F. Wilson

G. T. Yahr

G. L. Yoder

ORNL Central Research Library

Document Reference Section

\section{EXTERNAL DISTRIBUTION}

61. ARGONNE NATIONAL LABORATORY, 9700 South Cass Ave., Building 360 , IPNS Division, Argonne, IL 60439.

J. M. Carpenter

62. LOS ALAMOS NATIONAL LABORATORY, LER/ADTT, Los Alamos, NM 87545

A. Jason

W. Sommer (MS-E546)

63. Monroe Wechsler, 106 Hunter Hill Place, Chapel Hill, NC 27514-9128

64. BROOKHAVEN NATIONAL LABORATORY, Upton, NY 11973

W. Weng

M. Todowso

65. PAUL SCHERRER INSTITUTE, CH-5232, Villigen-PSI, Switzerland

G. Bauer 